\title{
Intensidade energética dos países integrantes do BRICS (Brasil, Rússia, Índia, China e África do Sul)
}

\section{Harine Matos Maciel' ${ }^{1}$, Ahmad Saeed Khan²}

1Programa de Pós-Graduação em Desenvolvimento e Meio Ambiente. Universidade Federal do Ceará (UFC). Instituto de Educação do Ceará. Avenida dos Paroaras, 88. Casa 8d. Condomínio Jardim Botânico 1. Passaré. Fortaleza-CE. Brasil. (CEP 60744-040). E-mail: harinematos@yahoo.com.br.

2Programa de Pós-Graduação em Desenvolvimento e Meio Ambiente e Economia Rural. Universidade Federal do Ceará (UFC). Centro de Ciências Agrarias. Departamento de Economia Agrícola. Campus do Pici. Pici. Fortaleza-CE. Brasil. (CEP 60440-970).

Resumo. A energia é fundamental para o crescimento e manutenção das atividades humanas. A intensidade energética mede a eficiência com que os países utilizam as energias disponíveis. O objetivo deste artigo foi analisar a intensidade energética dos países pertencentes ao BRICS (Brasil, Rússia, Índia, China e África do Sul) para os períodos de 2004, 2006, 2008, 2010, 2012 e 2014. Os dados utilizados foram de origem secundária obtidos no site da Agência Internacional de Energia. O método de análise utilizado foi o descritivo através das variáveis produção de energia, consumo de eletricidade, emissões de $\mathrm{CO}_{2}$, intensidade energética e autos suficiência energética global. No período analisado todos os países aumentaram a produção de energia. A China alcançou a maior produção. No consumo de eletricidade todos os países aumentaram e os maiores consumos foram alcançados, respectivamente, pela China e Rússia. A China e a Índia quase dobraram as emissões de $\mathrm{CO}_{2}$ nos anos analisados. Todos os países diminuíram a intensidade energética, com exceção do Brasil que obteve um pequeno aumento no último ano analisado. Mesmo com esse aumento, o Brasil é o país com a menor intensidade energética. Os resultados mostram a urgência em se modificar a composição da matriz energética dos países, principalmente os que mais poluem, buscando investimentos em áreas diversas de produção de energia, com ênfase nas energias limpas, capazes de abastecer a população com menos impactos ambientais.

Palavras-chaves: Energia; Dióxido de carbono; Intensidade energética.

Abstract. Energy intensity of BRICS countries (Brazil, Russia, India, China and South Africa). The energy is fundamental to the growth and maintenance of human activities. Energy intensity measures the efficiency with which countries use the available energy. The objective of this article was to analyze the energy intensity of the countries belonging to the BRICS (Brazil, Russia, India, China and South Africa) for the periods of 2004, 2006, 2008, 2010, 2012 and 2014. The data used were of secondary origin obtained on the website of the International Energy Agency. The

Recebido:

$14 / 10 / 2017$

Aceito:

28/12/2017

Publicado:

31/12/2017

Acesso aberto Artigo completo

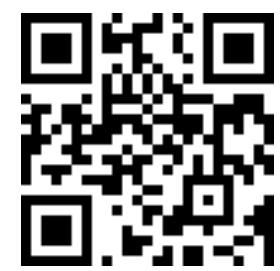

ORCID

() 0000-0003-3267-6198 Harine Matos Maciel

(1) 0000-0002-4079-7574 Ahmad Saeed Khan 
method of analysis used was the descriptive one through the variables energy production, electricity consumption, $\mathrm{CO}_{2}$ emissions, energy intensity and global energy self-sufficiency. In the period analyzed, all countries increased energy production. China has achieved the highest production. In electricity consumption, all countries increased and the highest consumption was achieved, respectively, by China and Russia. China and India nearly doubled $\mathrm{CO}_{2}$ emissions in the years under review. All countries decreased energy intensity, with the exception of Brazil, which had a small increase in the last year analyzed. Even with this increase, Brazil is the country with the lowest energy intensity. The results show the urgency to change the composition of the energy matrix of the countries, especially those that pollute the most, seeking investments in different areas of energy production, with an emphasis on clean energy, capable of supplying the population with less environmental impacts.

Keywords: Energy; Carbon dioxide; Energy Intensity.

\section{Introdução}

O ser humano tem provocado ao longo do tempo inúmeros impactos aos ambientes naturais. $\mathrm{O}$ avanço do crescimento econômico agravou os problemas ambientais como a contaminação da água, destruição da fauna e flora, uso intensivo de agrotóxicos, mau uso do solo, falta de técnicas adequadas de manejo dos animais, entre outros (Maciel e Khan, 2017).

Os homens usufruem de alguns bens que a natureza concede gratuitamente, como o ar, a água e a luz do sol. Não são esses os bens aos quais, na acepção corrente, chamam de riquezas. Os recursos naturais eram utilizados como mercadorias que poderiam ter reposição a qualquer momento, porém o uso desmedido mostrou que estes recursos são limitados e podem esgotar, além de influenciar diretamente a qualidade de vida da população através, por exemplo, do aumento de temperatura e da poluição excessiva (Say, 1986).

Em nível mundial, os assuntos referentes a economia eram o objetivo central das discussões dos governos, não havendo espaço para debates acerca do meio ambiente. Conforme Lopes (2001) uma das primeiras ações que estimularam este debate, foi a realização da Conferência da Biosfera em Paris, em 1968, que deu origem a $1^{\text {a }}$ Conferência das Nações Unidas sobre o Meio Ambiente e Desenvolvimento em 1972. Após essa conferência, a maioria dos países passou a se preocupar com a proteção ambiental. Não havia, entretanto, uma ação coordenada pelo governo ou por uma entidade responsável pela gestão ambiental, dificultando assim a promoção de ideias sobre o conservadorismo ambiental.

Conforme Bayardino (2004) a partir dessa conferência, quase todas as nações industrializadas promulgaram legislações e regulamentos ambientais. Além disso, criaram organismos ou ministérios encarregados do meio ambiente para enfrentar de maneira eficaz a degradação da natureza. No entanto, a sociedade também necessita fazer a sua parte, já que a crescente demanda por produtos e serviços contribui para o uso intensivo dos recursos energéticos, e muitos destes recursos são não renováveis como carvão e petróleo.

A energia é fundamental para o crescimento e manutenção das atividades humanas, porém esta não pode continuar degradando os ambientes naturais (Mendes, 2014). De acordo com a FAPESP (2007) alcançar um futuro de energia sustentável é um grande desafio para os próximos anos e possuir as tecnologias necessárias para reduzir os impactos causados ao meio ambiente não é suficiente se não forem disseminadas aos países que mais poluem o planeta. 
A intensidade energética mede a eficiência com que os países utilizam as energias disponíveis. Em muitos países como Brasil, China, Índia e Estados Unidos, segundo Goldemberg (1998) a intensidade energética tem se reduzido, apesar de não ser em nível suficiente para compensar o consumo excessivo de energia. Investir em eficiência energética deve ser uma prioridade de políticas públicas dos países.

É necessário e urgente que se modifique a relação atual entre o ser humano e a natureza, que é exploratória, pois se cria barreiras para o futuro ao utilizar de forma desmedida os recursos naturais, produzindo a escassez, poluindo o ambiente, desmatando, extinguindo espécies e aquecendo o planeta (Maciel e Khan, 2017).

A sustentabilidade precisa estar presente nas políticas públicas nacionais, mostrando a importância da preservação dos recursos naturais, através de ações como a implantação dos conceitos de economia verde, construção de edifícios verdes, projetos de reutilização de água, energia e reciclagem de lixo, eficiência nos transportes e na agricultura, tecnologias limpas, entre outros (MMA, 2014).

O aumento desenfreado da demanda por energia faz com que os países utilizem suas capacidades máximas de produção, poluindo assim o ambiente, já que, em geral, são utilizadas fontes poluidoras como o carvão e petróleo (EPE, 2014). No entanto o ser humano depende completamente do meio ambiente e todos, sem exceção, são responsáveis pela sua preservação.

Diante do exposto este artigo tem como objetivo analisar a intensidade energética dos países pertencentes ao BRICS (Brasil, Rússia, Índia, China e África do Sul) para os períodos de 2004, 2006, 2008, 2010, 2012 e 2014.

\section{BRICS e a intensidade energética}

Após a Revolução Industrial a capacidade do homem de intervir na natureza aumentou significativamente, e esta intervenção tem causado desequilíbrios ambientais crescentes em função da utilização de recursos naturais de forma mais rápida que a capacidade de reconstituição destes recursos (Pereira e Horn, 2009).

Ruddiman (2003) defende que o ser humano já contribuía antes da era industrial nas emissões de gases do efeito estufa. A visão moderna atribui papel significante às emissões humanas a partir da revolução industrial, apesar das emissões antrópicas em períodos pré-industriais serem muito menores que as atuais, o seu efeito cumulativo desde o início da prática da agricultura traz evidências para corroborar esta hipótese.

A Conferência de Estocolmo, em 1972, teve como principal objetivo alertar a sociedade sobre os riscos ambientais causados pelo modelo de desenvolvimento vigente (Lopes, 2001). Nos anos setenta e oitenta, de acordo com Pelicioni (1998) os países em desenvolvimento defendiam-se com o discurso de que era necessário poluir para alcançar o progresso e a riqueza.

Conforme a AIE (2016) a tecnologia avançou, mas diversos países continuaram utilizando fontes de energia poluidoras como os combustíveis fósseis e o carvão. O uso de fontes renováveis, como a energia eólica e a solar, já estava disseminado, porém os países em desenvolvimento, em particular grandes economias como Brasil, Rússia, Índia, China e África do Sul, tinham pequenas participações devido ao investimento dispendioso necessário para se adequar a estas fontes de energia.

O BRICS foi criado como uma categoria de países em desenvolvimento que estavam em um ritmo acelerado de crescimento econômico, são eles, Brasil, Rússia, Índia, China e África do Sul. De acordo com Leão (2012) são muitas as diferenças estruturais entre os países do BRICS, como: i) O Brasil é conhecido pela exportação de commodities, como a soja, minério de ferro, café, açúcar, etanol, celulose, carnes e suco de laranja; ii) A Rússia foi considerada no passado como grande potência industrial e hoje como exportador de petróleo e gás, e sua expansão econômica oscila com o valor 
dessas commodities; iii) A Índia vende para o exterior, serviços de alta tecnologia, com destaque para software; iv) A China apesar de manter mais da metade de sua população na área rural, já possui um amplo setor industrial e desenvolve um comércio internacional baseado na exportação de produtos com crescente teor tecnológico; v) África do Sul reproduz um modelo de exportações parecido, até certo ponto, com o do Brasil.

Juntos os BRICS somam $44 \%$ da população mundial (Santos, 2010). Além de possuírem grandes extensões territoriais, abundantes recursos naturais e energéticos e um acelerado crescimento econômico. Devido a isso surge questionamentos pertinentes ao futuro dos recursos naturais e a sua utilização, já que, segundo Meadows et al. (1972), caso esses países consumam o mesmo nível de recursos que as atuais potencias econômicas, o planeta alcançaria uma situação catastrófica. Segundo May (2008) as emissões anuais de $\mathrm{CO}_{2}$ do BRICS representam aproximadamente dois terços da média global.

De acordo com a AIE (2012), em 2010 o BRICS representou cerca de um quarto do PIB mundial, representaram 33\% do uso global de energia e $37 \%$ de emissões de $\mathrm{CO}_{2}$ provenientes da queima de combustível.

A China é o país que mais emite os gases do efeito estufa, seguido pelos Estados Unidos, Índia, Brasil e Rússia. Dos países pertencentes ao BRICS, apenas a África do Sul não consta entre os cinco maiores emissores mundiais (Banco Mundial, 2012).

Segundo BRICS (2013), os países que o compõe ocupam $30 \%$ do território global e são o lar de $45 \%$ da população mundial; além disso, a contribuição para o crescimento econômico global ao longo da última década chegou a $50 \%$, tornando este grupo de estados líderes no desenvolvimento econômico global.

A intensidade energética é representada pela razão entre o consumo total de energia de um país, em unidade de energia, e o PIB da economia, expresso em unidades monetárias, evidenciando o grau de eficiência da utilização energética em relação à riqueza do país, desta forma quanto menor o uso de energia por unidades monetárias, maior a eficiência da economia (Bartolo, 2008).

Conforme Schipper et al. (1990) um dos indicadores mais utilizados para comparações internacionais no âmbito da energia é a intensidade energética, que relaciona energia e PIB. De acordo com Cohen (2005) há outros indicadores também muito utilizados como a pegada ecológica, intensidade material e a curva de Kuznets ambiental, especialmente em se tratando de impactos macroeconômicos decorrentes de choques nos preços da energia.

Nos anos de 1990, as políticas energéticas não eram consideradas relevantes, já que ocorriam problemas graves como as crises econômicas. Somente depois dos anos 2000 os países começaram a colocar em pauta as políticas energéticas, já que graves problemas começaram a surgir como falhas no abastecimento e elevações sucessivas no preço do petróleo, forçando assim a busca por outras fontes de energia (Tolmasquim et al., 2007).

Os países desenvolvidos possuem menor intensidade energética que os países em desenvolvimento. Os países em desenvolvimento tendem a elevar a intensidade energética devido à adição de capacidade produtiva, além do elevado crescimento populacional que faz com que seja necessário a elevação do consumo de energia per capita (Miketa, 2001).

A intensidade energética mundial, medida por unidade do valor adicionado, vem registrando queda de aproximadamente 0,92\% ao ano, entre 1970 e 2000 (Patusco, 2002).

A política energética dos países do BRICS necessita ser colocada em pauta nas políticas ambientais para que o uso das energias limpas seja priorizado. No Brasil, de acordo com o IPEA (2015) a política energética era muito vulnerável e dependente de outros países, mas com investimentos no setor ocorreu a ampliação da capacidade de geração de energia e o desenvolvimento de fontes renováveis. Segundo a AIE (2007), o Brasil possui uma matriz energética limpa, pouco dependente 
de combustíveis fósseis (apenas 55\%), se comparada a matriz energética mundial (87\%). Outra vantagem da matriz energética brasileira é possuir maior participação de energia hidráulica e de biomassa do que a média mundial.

$O$ volume total das emissões de gases de efeito estufa caiu em mais de $40 \%$ desde o ano 2000 com a diminuição da taxa de desmatamento, porém as emissões provenientes do consumo de energia pelas indústrias e pelo transporte aumentaram. $\mathrm{O}$ Brasil tem alcançado grandes avanços na redução de sua pegada de carbono, mas a crescente demanda por mobilidade levou a uma duplicação da frota de veículos, elevando a demanda por energia e a emissão de gases do efeito estufa decorrente do setor de transportes e agravando pressões ambientais em vários centros urbanos. O país vem formulando um plano de adaptação às mudanças climáticas. Há consenso de que a mudança climática pode ter impactos negativos significativos sobre alguns setores da economia, notadamente a agricultura e a infraestrutura, exacerbando pressões existentes, a exemplo da escassez de água (OCDE, 2015).

Na Rússia a política ambiental durante muitos anos não ocupou uma posição de destaque. A população, em geral, não se importava com o assunto do aquecimento global, porque como o clima do país é muito frio, para eles o aumento das temperaturas trariam mais vantagens como um ambiente com temperaturas mais amenas. Porém, Tynkkynen e Aalto (2012) afirmam que com a extensão geográfica russa e a sua variação climática e topográfica, a Rússia tem potencial para se transformar em uma superpotência de energias renováveis.

Para construir uma imagem de maior responsabilidade ambiental, o governo em 2001 lançou a "Doutrina ecológica”. Em 2002, criou a lei de proteção ao meio ambiente, na qual foi enunciado o direito do indivíduo a um meio ambiente saudável, garantido pela harmonização de interesses econômicos e sociais do indivíduo, da sociedade e do Estado. A inserção da questão ambiental dentro das discussões de segurança tem feito com que o Estado russo privilegie a compreensão do meio ambiente, principalmente, em alguns poucos assuntos, como medidas de prevenção de desastre, modernização das indústrias, acordos bilaterais e introdução de novas tecnologias (Silva e Herz, 2012).

Na Índia ainda há muita exploração das florestas e o uso intensivo dos solos para atividades agrícolas, contribuindo assim para a degradação dos ambientes naturais. A industrialização e o aumento do setor de transportes também contribuem para a intensa poluição do ar. Porém, a proteção ambiental tem melhorado nos últimos anos devido à legislação ambiental e ao interesse da população em reverter essa situação. A governança ambiental passou a ter importância no país (Mello-Théry et al., 2010).

Em 1997, a Suprema Corte da Índia aprovou a decisão que exigiu de todos os serviços florestais no país a resolução no prazo de um ano, dos direitos existentes nas áreas protegidas indianas. Isso se traduziu em remoção das populações dentro de Parques Nacionais e reduziu o acesso aos recursos para aqueles que vivem em santuários da vida selvagem ou em áreas adjacentes das áreas protegidas (MelloThéry et al., 2010).

A Índia diminuiu o consumo de energias renováveis, 54\% (1991) para 48\% (2012), segundo dados do Banco Mundial (2012), apesar de estar investindo em sua expansão. Segundo Maciel e Khan (2017) um dos complicadores é que uma das maiores reservas de carvão do mundo é indiana e o país continua a utilizá-la intensamente, já que é sua principal fonte de energia. Os governantes adiaram 0 quanto puderam a assinatura de acordos referentes aos compromissos de limitar a emissão dos gases do efeito estufa, pois segundo eles a principal meta é diminuir a pobreza no país e para isso é necessário utilizar a sua principal fonte de energia e que os países ricos possuem maior responsabilidade com as mudanças climáticas.

Veríssimo e Nussbaum (2011) afirmam que na Índia quase todas as áreas florestais são de propriedade estatal e a lei 
florestal exige que a propriedade seja mantida como floresta. Mesmo assim muitos hectares são utilizados para aumentar a capacidade produtiva do país, através de geração de energia, desmatamentos e atividades de mineração.

A China, o maior poluidor dos gases do efeito estufa, de acordo com o Banco Mundial (2017), enfrenta graves problemas referentes, principalmente, à infraestrutura das cidades, já que utiliza intensamente 0 carvão para diversas atividades empresariais e domésticas, poluindo a água, o ar e gerando muito lixo. Há uma má gestão ambiental e por isso o governo tem investido bastante em educação ambiental não só nas escolas, mas também no ensino superior.

Foi nos anos 1970 que os chineses aprovaram a sua Lei de Proteção Ambiental, exigindo que cada novo projeto atendesse as regulamentações ambientais (Zago, 2014). Órgãos como o Ministério de Proteção Ambiental e atores não estatais são mais proativos com relação às mudanças climáticas e às medidas necessárias para enfrentá-las, mas gozam de baixo prestígio interno (Heggelund et al., 2010). Mostrando assim que ainda há barreiras em se tratar assuntos ambientais com o mesmo compromisso e empenho que se trata os assuntos econômicos, já que o crescimento econômico continua sendo o principal objetivo do país.

Segundo o relatório da ONU (2016), a China tem o objetivo de aumentar em $23 \%$ a cobertura de florestas até 2020 , reduzir $15 \%$ no consumo de energia e $23 \%$ no consumo de água, e para alcançá-los já construiu 1,5 bilhão de metros quadrados de prédios com eficiência energética em área urbana e o uso de veículos elétricos no país aumentou 45 vezes entre 2011 e 2015.

Em relação ao consumo de energias renováveis, a AIE (2015) afirmou que a China é o pais que mais emprega na indústria de energia renovável, com quase 3,9 milhões de postos de trabalhos ligados à energia solar, eólica e outras fontes verdes, porém essas ações ainda não são suficientes para que o país diminua suas emissões dos gases do efeito estufa.

A África do Sul utiliza o carvão para geração de energia, já que há grandes reservas no país (Fiori, 2014). Conforme Pegels (2010), a utilização de energia solar e eólica ainda é insignificante dentro do total gerado, ainda que consideradas de grande potencial devido à região geográfica que o país está inserido, com áreas que apresentam insolação intensa na maior parte do ano e também um regime de ventos favorável. Os principais obstáculos para a adoção atual dessas novas tecnologias na África do Sul são os preços ainda elevados nos investimentos iniciais, falta de mão de obra especializada e uma percepção de risco excessivamente elevada para investidores privados.

As mudanças climáticas e os problemas de abastecimento de energia trarão consequências sobre todos os países. O combate a essas alterações devem ser feitas através de políticas conjuntas mundiais, conscientizando a população de que é essencial proteger os ambientes naturais para as gerações presentes e futuras.

\section{Metodologia}

A pesquisa abrange os cinco países pertencentes ao BRICS (Brasil, Rússia, Índia, China e África do Sul). Os dados utilizados foram de origem secundária obtidos no portal da Internet da Agência Internacional de Energia (International Energy Agency - IEA), do período de 2004, 2006, 2008, 2010, 2012 e 2014.

O método de análise utilizado foi o descritivo, através das variáveis quantitativas contínuas produção de energia (milhões de toneladas equivalentes a óleo - Mtoe), consumo de eletricidade (terawatt hora Twh), emissões de $\mathrm{CO}_{2}$ (em milhões de toneladas de $\mathrm{CO}_{2}$ - mt de $\mathrm{CO}_{2}$ ), intensidade energética (consumo total de energia/PIB) e autossuficiência energética global (\%). A técnica descritiva utilizada foram as tabelas, organizando e resumindo as informações. 


\section{Resultados e discussão}

Nesta seção, apresenta-se a análise das variáveis produção de energia, consumo de eletricidade, emissões de $\mathrm{CO}_{2}$, intensidade energética e a autossuficiência energética global, para os países pertencentes ao BRICS nos anos de 2004, 2006, 2008, 2010, 2012 e 2014.

\section{Produção de energia}

A energia é essencial para a vida humana, e sem ela não teria ocorrido a evolução no modo de viver. Nos últimos anos surgiram diversos produtos e serviços, como eletrodomésticos e internet, que facilitaram o dia a dia, trazendo assim conforto e bem estar para a população.

No mundo, atualmente, o carvão mineral é a maior fonte para produção de energia elétrica, em sequência vem o gás natural, a hidroeletricidade, a energia nuclear e finalmente o petróleo e seus derivados. A grande utilização de combustíveis fósseis é explicada por quatro fatores principais: grande disponibilidade de recursos, particularmente do carvão mineral; competitividade econômica; viabilidade técnica e econômica do seu transporte e adequada tecnologia para aproveitamento energético. Outra característica relevante que justifica o uso desses combustíveis é a facilidade de produzir energia na forma de calor, e assim serem transformadas em outras formas de energia, por exemplo, elétrica, o que explica a grande utilização dos mesmos no passado, atualmente e ainda a tendência de permanecer no futuro (Morais, 2015).

No período analisado todos os países aumentaram a sua produção de energia (Tabela 1). A China alcançou a maior produção (1.563,14 megatonelada equivalente de petróleo - mtoe - 2004 para 2.593,11 mtoe - 2014), já que ser a maior população do mundo também contribui com este resultado, há também o contínuo crescimento econômico, aumentando assim o consumo de energia para o mercado interno, tanto para o uso doméstico como o uso industrial.

A Rússia ocupa a segunda posição no ranking, uma vez que o país possui um enorme potencial energético, além de uma demanda crescente por energia. De acordo com a AIE (2015) o país detém as maiores reservas de gás natural do mundo e também é rico em petróleo. Com toda essa riqueza natural a União Europeia é dependente, pois consome $70 \%$ do petróleo e $65 \%$ do gás exportados pela Rússia.

Tabela 1. Produção de Energia dos países pertencentes ao BRICS.

\begin{tabular}{lrrrrrr}
\hline & \multicolumn{5}{c}{ Produção de Energia (Mtoe) } \\
\cline { 2 - 7 } & $\mathbf{2 0 1 4}$ & $\mathbf{2 0 1 2}$ & $\mathbf{2 0 1 0}$ & $\mathbf{2 0 0 8}$ & $\mathbf{2 0 0 6}$ & \multicolumn{1}{c}{$\mathbf{2 0 0 4}$} \\
\hline África do Sul & 168,32 & 165,83 & 163,96 & 161,96 & 157,52 & 157,61 \\
Brasil & 267,25 & 251,92 & 246,62 & 228,18 & 206,32 & 182,46 \\
China & 593,11 & $2.492,96$ & $2.315,54$ & $2.029,09$ & $1.830,33$ & $1.563,14$ \\
Índia & 541,81 & 519,53 & 496,72 & 446,87 & 415,77 & 390,50 \\
Rússia & $1.305,68$ & $1.316,00$ & $1.279,37$ & $1.253,2$ & $1.227,00$ & $1.172,32$ \\
\hline
\end{tabular}

Fonte: AIE (2017).

A terceira maior produção é dos indianos. A Índia que passa por um contínuo crescimento econômico ainda é muito dependente de fontes não renováveis de energia como o carvão, mas o país começou a investir em fontes de energias renováveis.
O Brasil ficou na penúltima posição na produção de energia, houve um aumento de $46 \%$ no período analisado. Apesar do país possuir inúmeras riquezas naturais que facilitam a implantação de fontes de produção de energia renováveis, a produção 
de energia elétrica vem poluindo cada vez mais (Goldemberg e Lucon, 2007).

Conforme Morais (2015), o Brasil encontra-se em um período de desenvolvimento econômico incerto, porém mesmo assim a demanda por energia elétrica é crescente. Portanto, é necessário destacar que o país possui um vasto potencial na produção de combustíveis fósseis e faz parte do grupo de países em que a produção de eletricidade é proveniente, na sua maior parte, de usinas hidrelétricas. No Brasil, grande parte da população tem acesso ao recurso da eletricidade, mesmo que em muitos casos de maneira insuficiente, mas o problema nacional está na distribuição dos recursos energéticos. O país possui uma abundância de recursos que em muitos casos estão distantes das grandes concentrações de pessoas, que são os grandes centros urbanos onde está localizada mais de $80 \%$ da população brasileira.

E o menor aumento da produção de energia foi da África do Sul, menos de $10 \%$, passando de 157,61 mtoe (2004) para
168,32 mtoe (2014), devido à escassez de energia da região, sendo necessários fortes investimentos para o desenvolvimento deste setor, além do estímulo à produção de energia renovável, já que o país possui as riquezas naturais necessárias para este tipo de geração de energia.

\section{Consumo de eletricidade}

$\mathrm{O}$ crescimento das economias fez com que o consumo da população acelerasse continuamente, trazendo uma sobrecarga para a produção de energia mundial. Todos os países aumentaram o consumo de eletricidade nos anos analisados. Os maiores consumos foram alcançados, respectivamente, pela China e Rússia (Tabela 2), ambos dobraram a quantidade consumida de eletricidade. Apenas a África do Sul não apresentou um crescimento contínuo, já que houve uma diminuição entre os anos de 2010 e 2014, porém apresenta um aumento quando se compara o ano inicial (2004 - 217,06 TWh) com o ano final (2014 - 228,98 TWh).

Tabela 2. Consumo de Eletricidade dos países pertencentes ao BRICS.

\begin{tabular}{lrrrrrr}
\hline & \multicolumn{5}{c}{ Consumo de Eletricidade (TWh) } \\
\cline { 2 - 7 } África do Sul & \multicolumn{1}{c}{$\mathbf{2 0 1 4}$} & $\mathbf{2 0 1 2}$ & $\mathbf{2 0 1 0}$ & $\mathbf{2 0 0 8}$ & \multicolumn{1}{c}{$\mathbf{2 0 0 6}$} & \multicolumn{1}{c}{$\mathbf{2 0 0 4}$} \\
\cline { 2 - 7 } Brasil & 228,98 & 230,67 & 232,66 & 232,23 & 228,96 & 217,06 \\
China & 531,23 & 498,51 & 464,65 & 428,20 & 398,95 & 359,95 \\
Índia & $5.357,55$ & $4.693,65$ & $3.937,66$ & $3.240,60$ & $2.673,19$ & $2.055,37$ \\
Rússia & $1.042,33$ & 915,46 & 790,43 & 673,87 & 593,48 & 510,15 \\
\hline
\end{tabular}

Fonte: AIE (2017).

A China, o país com a maior população do BRICS, aumentou quase $160 \%$ nos dez anos analisados, passando de 2.055,37 TWh (2004) para 5.357,55 TWh (2014). De acordo Pereira et al. (2016) o consumo de eletricidade dos chineses aumentou devido ao crescimento populacional e econômico, aumentando consequentemente a demanda por produtos com alta tecnologia e que dependem de energia para o seu funcionamento.
O segundo maior consumo de eletricidade é dos indianos, houve um aumento de pouco mais de $100 \%$. A Índia é um dos países que mais cresce economicamente nos últimos anos, mas ainda há muita concentração de renda e pobreza no país, prejudicando assim a distribuição mais igualitária de energia.

Segundo a AIE (2014) o consumo de energia per capita da Índia é um terço da média global, indicando, potencialmente, 
maior demanda de energia no longo prazo, já que o país continua sua trajetória de desenvolvimento econômico. Projeta-se que a Índia e a China serão responsáveis por cerca da metade do crescimento global da demanda de energia até 2040, com a demanda de energia da Î́ndia crescendo a $2,8 \%$ ao ano.

A Rússia alcançou o terceiro maior consumo de eletricidade. Os russos têm investido na geração de energias renováveis, já que sua população demanda cada vez mais energia. A AIE (2011) estima que, até 2035, a Rússia precisará investir um total de US\$ 2,5 trilhões, a fim de satisfazer as necessidades de abastecimento de energia.

O consumo de eletricidade no Brasil aumentou em torno de $50 \%$ nos anos analisados, mas nos últimos anos devido às crises financeiras e hídricas, o preço da energia tem aumentado continuamente. De acordo com o Ministério de Minas e Energia (2016), o consumo nacional de energia elétrica no Brasil caiu 0,9\% em 2016, puxado principalmente pela indústria (-2,9\%). Em dezembro de 2016, porém, a indústria teve alta de $0,9 \%$ no consumo, enquanto o setor comercial continuou em queda, de (-3,3\%), o que ajudou a registrar estabilidade no consumo total $(+0,5 \%)$. $\mathrm{O}$ consumo de energia elétrica das residências exibiu aumento de 2,6\% em dezembro, com destaque para as regiões Sudeste $(+3,3 \%)$ e Sul $(+5,4 \%)$.

A África do Sul foi o país do BRICS que obteve o menor aumento no consumo de eletricidade, em torno de $6 \%$. O país tem muito potencial para o uso das energias renováveis, mas ainda não há investimento suficiente para que este tipo de energia consiga alcançar grande parte da população, principalmente as mais necessitadas de energia elétrica.

A África do Sul possui pequenos depósitos de petróleo e gás natural, utilizando os seus vastos depósitos de carvão para suprir sua necessidade de energia elétrica. De acordo com a IEA, quase $70 \%$ do total de energia da África do Sul vem do carvão. O consumo de eletricidade no país cresceu $20 \%$ na última década, o que tem gerado sobrecarga na infraestrutura de abastecimento e sucessivas crises de energia, que prejudicaram a atividade de vários setores da economia. Apesar de possuir uma taxa de $75 \%$ de eletrização, a maior taxa na África Subsaariana, apenas 55\% da sua população rural possui acesso à energia, o que equivale a aproximadamente 12,5 milhões de pessoas (AIE, 2014).

\section{Emissões de $\mathrm{CO}_{2}$}

A Revolução Industrial modificou a forma de produzir. O que antes era feito de modo artesanal e em poucas quantidades, passou a ser produzido através de máquinas e em maiores volumes, utilizando assim mais fontes de energia como carvão e petróleo, fontes de energia não renováveis. Porém, devido ao uso desenfreado desses recursos, estão se tornando escassos, sendo necessário aumentar o uso de recursos renováveis como energia eólica, solar, hidráulica e biomassa. Contribuindo assim para diminuir a poluição causada por estas fontes não renováveis de energia.

As fontes fósseis de energia predominam até hoje na matriz energética mundial e de todos os países individualmente. Em 2001, o mundo consumiu quase $80 \%$ de energias fósseis em um total de 10,2 bilhões de toneladas equivalentes de petróleo. A principal delas é o petróleo (35\% do total), mas as parcelas de carvão (23\%) e gás natural (22\%) também são bastante significativas. A energia move todo ano altas cifras econômicas, algo em torno de 1,5 trilhão de dólares. As energias fósseis recebem enormes somas de subsídios, das mais variadas formas, algo como 151 bilhões de dólares ao ano entre 1995 e 1998. Os renováveis receberam no mesmo período 9 bilhões de dólares ao ano (Goldemberg e Lucon, 2007).

Devido à grande demanda por energia, as emissões de $\mathrm{CO}_{2}$ só tem aumentado nos últimos anos, contribuindo assim para o aquecimento global. A solução são as mudanças no uso de energia, passando a utilizar cada vez mais fontes de energias renováveis, como a solar e a eólica. 
A China e a Índia quase dobraram as emissões de $\mathrm{CO}_{2}$ nos anos analisados (Tabela 3). A China, atualmente, é o maior poluidor do planeta, e Brasil, Índia e Rússia também estão no topo da lista de maiores emissores mundiais de gases do efeito estufa.

A China é o maior produtor de energia hidrelétrica no mundo. Em 2009, foram gerados 616 TWh, que contribuíram com $16,7 \%$ da eletricidade produzida no país (IEA, 2011). O país é também líder global em energia eólica, possuindo uma capacidade instalada de 62,4 GW). Quanto à energia solar térmica para aquecimento de água, a China é a nação que possui a maior potência térmica instalada, de 101,5 GWt, sete vezes maior que a detida pelo segundo colocado e 27 vezes superior à capacidade brasileira. Além disso, a China é o maior fabricante de painéis fotovoltaicos, alcançando uma participação de 55\% do mercado mundial em 2010 (REN21, 2011). Porém, mesmo com essas lideranças, ainda continua sendo o país que mais emitem gases do efeito estufa.

Tabela 3. Total de emissões de $\mathrm{CO}_{2}$ dos países pertencentes ao BRICS.

\begin{tabular}{lcccccc}
\hline & \multicolumn{7}{c}{ Emissões de $\mathbf{C O}_{\mathbf{2}}\left(\mathbf{M t}\right.$ de $\left.\mathbf{C O}_{\mathbf{2}}\right)$} \\
\cline { 2 - 7 } & $\mathbf{2 0 1 4}$ & $\mathbf{2 0 1 2}$ & $\mathbf{2 0 1 0}$ & $\mathbf{2 0 0 8}$ & $\mathbf{2 0 0 6}$ & $\mathbf{2 0 0 4}$ \\
\hline África do Sul & 437,37 & 407,69 & 406,74 & 423,31 & 373,96 & 375,43 \\
Brasil & 476,02 & 422,24 & 370,53 & 347,89 & 314,03 & 309,77 \\
China & $9.086,96$ & $8.620,97$ & $7.707,05$ & $6.608,48$ & $5.912,88$ & $4.724,22$ \\
Índia & $2.019,67$ & $1.790,76$ & $1.594,26$ & $1.345,47$ & $1.150,72$ & $1.028,27$ \\
Rússia & $1.467,55$ & $1.550,82$ & $1.528,92$ & $1.553,56$ & $1.537,44$ & $1.487,97$ \\
\hline
\end{tabular}

Fonte: AIE (2017).

A Índia ainda não possui um consumo significativo de energias renováveis, apesar de estar investindo em sua expansão. Um dos complicadores é que uma das maiores reservas de carvão do mundo é indiana e o país continua a utilizála intensamente, já que é sua principal fonte de energia. Os governantes adiaram 0 quanto puderam a assinatura de acordos referentes aos compromissos de limitar a emissão dos gases do efeito estufa, pois segundo eles a principal meta é diminuir a pobreza no país e para isso é necessário utilizar a sua principal fonte de energia e que os países ricos possuem maior responsabilidade com as mudanças climáticas.

A Rússia obteve uma pequena diminuição, passando de 1.487,97 Mt de $\mathrm{CO}_{2}$ (2004) para $1.467,55 \mathrm{Mt}$ de $\mathrm{CO}_{2}$ (2014), apesar de ter obtido aumentos durante o período analisado e ocupar a terceira posição entre os países do BRICS relativo às emissões de $\mathrm{CO}_{2}$. Conforme Tynkkynen e Aalto (2012) a Rússia tem potencial para se transformar em uma superpotência de energias renováveis, já que possui grandes extensões territoriais e variações climáticas e topográficas.

Além de ocupar uma posição relevante no que tange ao fornecimento energético, a Rússia é um dos maiores consumidores mundiais de energia de origem fóssil, portanto as suas decisões de política energética têm implicações para a segurança energética e a sustentabilidade do meio ambiente, em uma dimensão global (AIE, 2011).

O Brasil também figura entre os maiores emissores de $\mathrm{CO}_{2}$ mundiais. No período analisado ocorreu um aumento de um pouco mais de $50 \%$, mostrando o crescimento contínuo nas emissões de um dos gases que mais contribuem para o efeito estufa. Em contrapartida com este aumento o Brasil busca cada vez mais aumentar o uso de fontes renováveis de energia.

Conforme o MMA (2015), em 10 anos, o uso de energia renovável cresceu $30 \%$, passando de $2,8 \%$ de toda a oferta de energia interna em 2004 para 4,1\%, em 2014. Essa expansão da oferta de energia 
renovável não foi suficiente para fazer crescer o consumo de energias renováveis no Brasil, mostrando-se urgente a necessidade de um maior esclarecimento da importância do uso dessas energias, além de estímulos através de políticas públicas para que empresas e sociedade em geral tornemse adeptos e defensores ao uso da energia renovável.

Outro ponto também que contribui de forma negativa para o aumento das emissões de $\mathrm{CO}_{2}$ no Brasil é a diminuição das áreas florestais, que passaram de 63,9\% nos anos 1990 para 58,07\% no ano de 2012, devido aos desmatamentos que ocorrem com frequência na região amazônica. Segundo a FAO (2015), o Brasil lidera o ranking de desmatamentos. O país perdeu 984 mil hectares de florestas por ano no período. A África e a América do Sul são os continentes com a maior perda anual líquida de florestas no período considerado no relatório, com 2,8 milhões e 2 milhões de hectares, respectivamente. A principal causa é a mudança do uso do solo, a conversão de terras florestais para atividades como a agricultura.

A África do Sul aumentou suas emissões de $\mathrm{CO}_{2}$ entre os anos de 2004 e 2014. O país tem buscado investir em projetos de energia renovável. De acordo com o Banco Mundial (2016) a escassez de energia na África prejudica o crescimento econômico do continente e a adoção de tecnologias limpas, o uso de energias renováveis, como a solar e a hidráulica, pode auxiliar nesse desenvolvimento, já que os recursos naturais neste continente são pouco explorados e há grandes rios, desertos ensolarados e planaltos com ventos constantes.

\section{Intensidade energética}

$\mathrm{O}$ estudo da intensidade energética é significante para compreender o modelo de produção e consumo de energia, avaliando assim se estão sendo eficientes ou não. A intensidade elevada indica uma baixa eficiência na transformação de energia em riqueza para os países. Desta forma, sua análise é essencial para a formulação de políticas públicas na busca pelo uso eficiente da energia e consequentemente o ganho de competitividade.

O inverso da eficiência energética é a intensidade energética. A eficiência energética é a melhora na produção de determinado bem ou serviço a partir de quantidades reduzidas de insumos utilizados na produção. Na economia, levando em consideração todos os setores produtivos, a eficiência energética não é um conceito significativo devido à natureza heterogênea da produção, diferenças estas que podem ser em produtos, processos e equipamentos. Por outro lado, comparações a respeito da intensidade energética são mais facilmente percebidas (Salazar, 2012).

A intensidade energética mostra 0 esforço dos países em continuar se desenvolvendo, buscando aprimorar os processos produtivos através de equipamentos mais eficientes e tecnologias mais modernas. Segundo Pinto $\mathrm{Jr}$ et al. (2007), as variações da intensidade energética podem ser atribuídas a diversos fatores entre eles: migrações demográficas da área rural para áreas urbanas, mudanças estruturais na economia visando às indústrias menos energo-intensivas, expressivo crescimento de setor de serviços, melhoria da eficiência no uso da energia e substituição de energéticos.

A Tabela 4 mostra a intensidade energética (consumo total de energia/PIB) dos países do BRICS. Todos diminuíram a intensidade energética no período analisado, com exceção do Brasil que obteve um pequeno aumento no último ano analisado. Mesmo com esse aumento, o Brasil é o país com a menor intensidade energética.

A intensidade energética no Brasil nos últimos anos tem sido em média de 0,12 toe/thousand 2005 USD. Conforme a AIE (2013) esse valor da intensidade energética brasileira está próximo aos valores médios de economias desenvolvidas da Europa (0,11 toe/thousand 2005 USD). Mostrando que os esforços brasileiros para melhorar a matriz energética do país está alcançando resultados satisfatórios, através, principalmente, do investimento em tecnologias limpas. 
Tabela 4. Intensidade energética.

\begin{tabular}{lcccccc}
\hline & \multicolumn{7}{c}{ (TPES/GDP) (toe/Thousand 2005 USD) } & \\
\cline { 2 - 6 } & $\mathbf{2 0 1 4}$ & $\mathbf{2 0 1 2}$ & $\mathbf{2 0 1 0}$ & $\mathbf{2 0 0 8}$ & $\mathbf{2 0 0 6}$ & $\mathbf{2 0 0 4}$ \\
\hline África do Sul & 0,35 & 0,35 & 0,38 & 0,40 & 0,40 & 0,42 \\
Brasil & 0,13 & 0,12 & 0,12 & 0,12 & 0,12 & 0,12 \\
China & 0,35 & 0,39 & 0,42 & 0,43 & 0,50 & 0,50 \\
Índia & 0,39 & 0,41 & 0,42 & 0,43 & 0,46 & 0,48 \\
Rússia & 0,40 & 0,42 & 0,42 & 0,41 & 0,48 & 0,50 \\
\hline
\end{tabular}

Fonte: AIE (2017). Toe = tonelada de óleo equivalente; TPES = fornecimento total de energia primária.

No ano de 2014, a Rússia obteve a maior intensidade energética, já que este país é um dos maiores consumidores mundiais de energia originárias de fontes não renováveis. $\mathrm{O}$ aumento da intensidade energética pode significar que a tecnologia utilizada não foi eficiente ou que houve um aumento do uso da capacidade instalada.

A possibilidade de aumento da eficiência energética, na Rússia, é maior do que em quase todos os outros países. Segundo estimativas haveria potencial para economizar gás natural, petróleo e carvão, que juntos representariam $46 \%$ dos gastos do país com energia no ano de 2008. A IEA calcula que $11 \%$ da que energia elétrica gerada seja perdida somente nos sistemas de transmissão e distribuição (AIE, 2011).

A exploração de todo potencial do incremento da eficiência energética e da economia de energia tem como benefício a liberação de parte da produção de hidrocarbonetos, que hoje atende ao mercado interno, para a exportação e pode gerar uma receita adicional de US\$ 84112 bilhões (Tynkkynen e Aalto, 2012). Com efeito, a atual oferta de energia russa seria capaz de suportar um nível maior de produção, isto é, crescimento econômico sem a necessidade de aumento do consumo de energia e dos investimentos para ampliação da oferta (AIE, 2011).

Um dos desafios da política energética russa é conseguir estimular os investimentos em eficiência energética. Boa parte da capacidade industrial do país foi instalada há décadas, desse modo opera com equipamentos obsoletos e altamente ineficientes (Charap e Safonov, 2010).
A Índia ocupou o segundo lugar no ranking de intensidade energética. Raj et. al (2010) afirma que mesmo a Îndia sendo um país consumidor, depara-se com vários desafios relativamente a segurança energética como a rápida urbanização, industrialização, o aumento dos rendimentos e a crescente utilização dos produtos de grande consumo energético fazem com que a capacidade de exploração e produção dos recursos indiano sejam limitados. A IEA (2013) refere que, em 2030, 147 milhões de indianos continuarão a não ter acesso à eletricidade e 730 milhões não terão instalações de cozinha limpas.

África do Sul e China empataram no terceiro lugar no ranking, apesar da China ter em média os maiores valores de intensidade energética, pois seu ritmo de produção e crescimento também são superiores aos africanos. Os altos valores alcançados pela intensidade energética africana deveram-se, principalmente, ao elevado uso do carvão no processo produtivo. Sendo importante investir na África do Sul nas fontes de energias renováveis, já que estas são abundantes, necessitando apenas de investimentos para que a sua capacidade energética continue alta, mas com energias que poluem menos 0 ambiente.

Para complementar a análise da intensidade energética, é significativa a análise da autossuficiência energética, pois esta é almejada por todos os países, já que alcançá-la significa ter uma matriz energética diversificada e um baixo custo de produção. Na Tabela 5, tem-se a autos 
suficiência energética global dos países do BRICS.

O Brasil (87\% em 2004 para 88\% em 2014) e a Rússia (181\% em 2004 e 182\% em 2014) foram os únicos países que apresentaram um pequeno aumento na autossuficiência energética global. A Rússia e a África do Sul alcançaram os melhores resultados quando comparados aos outros países pertencente do BRICS. Uma das razões que levaram a Rússia a ter este bom resultado deve-se ao fato de ser um dos principais fornecedores de óleo e gás do mundo. Já na África do Sul a grande quantidade de rios e lagos facilita a construção de usinas hidrelétricas.

Tabela 5. Autossuficiência energética global (\%).

\begin{tabular}{lcccccc}
\hline & $\mathbf{2 0 1 4}$ & $\mathbf{2 0 1 2}$ & $\mathbf{2 0 1 0}$ & $\mathbf{2 0 0 8}$ & $\mathbf{2 0 0 6}$ & $\mathbf{2 0 0 4}$ \\
\hline África do Sul & 116 & 120 & 116 & 110 & 124 & 123 \\
Brasil & 88 & 89 & 93 & 92 & 93 & 87 \\
China & 84 & 85 & 88 & 91 & 92 & 95 \\
Índia & 66 & 69 & 72 & 74 & 92 & 79 \\
Rússia & 182 & 178 & 186 & 182 & 183 & 181 \\
\hline
\end{tabular}

Fonte: AIE (2017).

O Brasil possui grandes riquezas naturais que facilitam o uso de energias renováveis. A energia elétrica brasileira produzida pelas hidrelétricas auxilia na geração de energia a custos baixos. Segundo a ANP (2015) o Brasil reconquistou a chamada "autossuficiência volumétrica" de petróleo devido ao crescimento da produção e ao avanço da Petrobras e das petroleiras privadas. Porém, o efeito da retomada da autossuficiência tende a ser mais simbólico que prático, uma vez que o parque de refino não dá conta da demanda local por combustíveis e ainda depende de uma fração de petróleo estrangeiro.

A China e a Índia diminuíram sua autossuficiência energética, apesar de economicamente estarem em constante evolução, aumentando assim a demanda e a oferta por energia, mas estes países além de serem os principais produtores de carvão, também são os principais importadores. Mostrando assim a necessidade de se tornar mais eficiente a matriz energética destes países, buscando investimentos em áreas diversas de produção de energia, principalmente em energias limpas.

\section{Considerações finais}

No período analisado todos os países aumentaram a produção de energia. A China alcançou a maior produção. E o menor aumento da produção de energia foi da África do Sul, devido à escassez de energia da região, sendo necessários fortes investimentos para o desenvolvimento deste setor.

No consumo de eletricidade todos os países aumentaram e os maiores consumos foram alcançados, respectivamente, pela China e Rússia, ambos dobraram a quantidade consumida de eletricidade. A África do Sul foi o país do BRICS que obteve o menor aumento no consumo de eletricidade. O país tem muito potencial para o uso das energias renováveis, mas ainda não há investimento suficiente para que este tipo de energia consiga alcançar grande parte da população, principalmente as mais necessitadas de energia elétrica.

Devido à grande demanda por energia as emissões de $\mathrm{CO}_{2}$ só tem aumentado nos últimos anos, contribuindo assim para o aquecimento global. A China e 
a Índia quase dobraram as emissões de $\mathrm{CO}_{2}$ nos anos analisados. A China, atualmente, é o maior poluidor do planeta, e Brasil, Índia e Rússia também estão no topo da lista de maiores emissores mundiais de gases do efeito estufa.

A intensidade energética mede a eficiência com que os países utilizam as energias disponíveis e mostram o esforço dos países em continuar se desenvolvendo, buscando aprimorar os processos produtivos através de equipamentos mais eficientes e tecnologias mais modernas.

Todos os países pertencentes ao BRICS diminuíram a intensidade energética no período analisado, com exceção do Brasil que obteve um pequeno aumento no último ano analisado. Mesmo com esse aumento, o Brasil é o país com a menor intensidade energética.

No ano de 2014, a Rússia obteve a maior intensidade energética, já que este país é um dos maiores consumidores mundiais de energia originárias de fontes não renováveis. A Índia ocupou o segundo lugar no ranking de intensidade energética. África do Sul e China empataram no terceiro lugar no ranking, apesar da China ter em média os maiores valores de intensidade energética, pois seu ritmo de produção e crescimento também são superiores aos africanos. Os altos valores alcançados pela intensidade energética africana devem-se, principalmente, ao elevado uso do carvão no processo produtivo.

Em relação à autossuficiência energética, o Brasil e a Rússia foram os únicos países que apresentaram um pequeno aumento na autossuficiência energética global. A Rússia e a África do Sul alcançaram os melhores resultados quando comparados aos outros países pertencente do BRICS. Uma das razões que levaram a Rússia a ter este bom resultado se deve ao fato de ser um dos principais fornecedores de óleo e gás do mundo. Já na África do Sul a grande quantidade de rios e lagos facilita a construção de usinas hidrelétricas.

A China e a Índia diminuíram sua autossuficiência energética, apesar de economicamente estarem em constante evolução, aumentando assim a demanda e a oferta por energia, mas estes países além de serem os principais produtores de carvão, também são os principais importadores. Mostrando a urgência em se modificar a composição da matriz energética dos países, principalmente os que mais poluem, buscando investimentos em áreas diversas de produção de energia, com ênfase nas energias limpas, capazes de abastecer a população com menos impactos ambientais.

\section{Declaração de conflito de interesse}

Os autores declaram não haver conflito de interesse.

\section{Referências}

AIE - Agência Internacional de Energia. Dados estatísticos. 2017. Disponível em: $<$ https://www.iea.org/statistics/>. Acesso em: 01 ago. 2017.

AIE - Agência Internacional de Energia. Uso de fontes renováveis. 2016. Disponível em: <https://www.iea.org/topics/renewables/>.

Acesso em: 18 set. 2017.

AIE - Agência Internacional de Energia. China e as energias renováveis. 2015. Disponível em: $<$ https://www.iea.org/>. Acesso em: 18 set. 2017.

AIE - Agência Internacional de Energia. Dados sobre produção de energia dos países pertencentes ao BRICS. 2014. Disponível em: <https://www.iea.org>. Acesso em: 20 set. 2017.

AIE - Agência Internacional de Energia. Intensidade Energética no Brasil. 2013. Disponível em: <https://www.iea.org>. Acesso em: 30 set. 2017.

AIE - Agência Internacional de Energia. BRICS e as emissões de gases. 2012. Disponível em $<$ https://www.iea.org $>$. Acesso em: 12 set. 2017.

AIE - Agência Internacional de Energia. Eficiência Energética na Rússia. 2011. Disponível em: <https://www.iea.org>. Acesso em: 01 ago. 2017.

AIE - Agência Internacional de Energia. Matriz energética brasileira. 2007. Disponível em $<$ https://www.iea.org>. Acesso em: 09 set. 2017.

ANP - Agência Nacional do Petróleo, Gás Natural e Biocombustíveis. Brasil retoma 
autossuficiência em petróleo. 2015. Disponível em: $\quad<$ http://www.gazetadopovo.com.br/ economia/brasil-retoma-autossuficiencia-empetroleo-er2q41s6vehb2xguo4ud4i8s0>. Acesso em: 20 set. 2017.

Banco Mundial. China o país que mais emite gases do efeito estufa. 2017. Disponível em <http://www.worldbank.org $>$. Acesso em: 14 set. 2017.

Banco Mundial. África do Sul e as energias renováveis. 2016. Disponível em <http://www.worldbank.org>. Acesso em: 12 set. 2017.

Banco Mundial. Países que mais emitem gases do efeito estufa. 2012. Disponível em <http://www.worldbank.org>. Acesso em: 10 set. 2017.

Bartolo, T. D. Relação entre o índice de intensidade energética e a evolução das emissões de $\mathrm{CO}_{2}$ no Brasil (1980-2005). Rio de Janeiro: Universidade Federal do Rio de Janeiro, 2008. (Monografia).

Bayardino, R. A. A Petrobras e o desafio da sustentabilidade ambiental. Rio de Janeiro: Universidade Federal do Rio de Janeiro, 2004. (Monografia). Disponível em: <http://www.ie.ufrj.br/gema/pdfs/a_petrobras_e _o_desafio_da_sustentabilidade_ambiental.pdf $>$ . Acesso em: 23 out. 2017.

BRICS. Fifth BRICS summit. Durban. 2013. Disponível em: <http://www.brics5.co.za> Acesso em: 30 set. 2017.

Charap, S.; Safonov, G. Climate change and role of energy efficiency. In: Aslund, A.; Guriev, S.; Kuchins, A. (Orgs.). Russia after the global economic crisis. Washington: Peterson Institute for International Economics, 2010.

Cohen, C. Padrões de consumo, energia e meio ambiente. Rio de Janeiro: Universidade Federal Fluminense, 2005. (Textos para discussão). Disponível em: <http://www.uff.br/ econ/download/tds/UFF_TD185.pdf $>$. Acesso em: 23 out. 2017.

EPE - Empresa de Pesquisa Energética. Estudos de Demanda de Energia 2050. Nota Técnica DEA 13/14. Rio de Janeiro, 2014. Disponível em: $\quad<$ http://www.epe.gov.br/Estudos/ Documents/DEA 13-14 Demanda de Energia 2050.pdf>. Acesso em: 23 set. 2017.

FAO - Food and Agriculture Organization of the United Nations. As florestas ainda cobrem 31\% da superfície da Terra. 2015. Disponível em: <http://www.fao.org/brasil/pt/>. Acesso em: 23 set. 2017.
FAPESP - Fundação de Amparo à Pesquisa do Estado de São Paulo. Um futuro com energia sustentável: iluminando o caminho. São Paulo: FAPESP, 2007. Disponível em: <http://www.fapesp.br/publicacoes/energia.pdf> . Acesso em: 23 out. 2017.

Fiori, J. L. História, estratégia e desenvolvimento: para uma geopolítica do capitalismo. São Paulo: Boitempo, 2014.

Goldemberg, J. Energia e desenvolvimento. Estudos Avançados, v. 12, n. 33, p. 7-15, 1998. https://doi.org/10.1590/S0103-40141998000200002

Goldemberg, J.; Lucon, O. Energias renováveis: um futuro sustentável. Revista USP, n. 72, p. 6-15, 2007. Disponível em: $<$ http://www.revistas.usp.br/revusp/article/view/ 13564/15382>. Acesso em: 23 out. 2017.

Heggelund, G.; Andresen, S.; Buan, I. F. Chinese climate policy: domestic priorities, foreign policy, and emerging implementation. In: Harrison, K.; Sundstrom, L. M. (Ed.). Global commons, domestic decisions: the comparative politics of climate change. Massachusetts: The MIT Press, 2010. p. 229259.

Howarth, R. B.; Geller, H.; Schipper, L. United States energy use from 1973 to 1987: the impacts of improved effciency. Annual Reviews Energy, v. 15, p. 455-504, 1990. https://doi.org/10.1146/annurev.eg.15.110190.0 02323

IPEA - Instituto de Pesquisa Econômica Aplicada. Brasil investe pouco em energias alternativas. Rio de Janeiro, IPEA, 2015. Disponível em: <http://www.ipea.gov.br/ desafios/index.php?option=com_content\&view =article\&id=3154\&catid=28\&Itemid=39>.

Acesso em: 23 out. 2017.

Leão, V. C. BRICS: identidade e agenda econômica - Notas de um observador diplomático. In: Pimentel, J. V. S. (Org.). O Brasil, os BRICS e a agenda internacional. 2. ed. rev. amp. Brasília: Fundação Alexandre de Gusmão, 2013. Disponível em: <http://funag.gov.br/loja/download/1032-

Brasil_os_BRICS_e_a_agenda_internacional_O .pdf>. Acesso em: 10 set. 2017.

Lopes, S. B. Arranjos institucionais e a sustentabilidade de sistemas agroflorestais: uma proposição metodológica. Porto Alegre: Universidade Federal do Rio Grande do Sul, 2001. (Dissertação de mestrado). Disponível em: <http://www.lume.ufrgs.br/bitstream/handle /10183/2677/000324691.pdf $>$. Acesso em: 23 out. 2017. 
Maciel, H. M.; Khan, A. S. O índice de ecoeficiência em âmbito internacional: uma análise comparativa do desempenho de 51 países entre os anos de 1991 a 2012. Sustentabilidade em Debate, v. 8, n. 1, p. 125-140, 2017. Disponível em: $<$ http://periodicos.unb.br/index.php/sust/article/ viewFile/21089/18159>. Acesso em: 23 out. 2017.

May, P. H. Como superar as condições entre crescimento e sustentabilidade? Inovações institucionais nos BRICS. In: Dupas, G. Meio ambiente e crescimento econômico: tensões estruturais. São Paulo: Editora da UNESP, 2008.

Meadows, D. H; Meadows, D. L; Randers, J.; Behrens, W. W. The limits to growth. Nova Iorque: Universe Books, 1972. Disponível em: <http://www.donellameadows.org/wp-content/ userfiles/Limits-to-Growth-digital-scanversion.pdf>. Acesso em: 23 out. 2017.

Mello-Théry, N. A.; Landy, F.; Zérah, M.-H. Políticas ambientais comparadas entre países do sul: pressão antrópica em áreas de proteção ambiental urbanas. Revista Mercator, v. 9, n. 20, p. 197-215, 2010. https://doi.org/10.4215/ RM2010.0920.0013

Mendes, C. A. N. Consumo de energia e crescimento econômico: uma relação em estudo com foco nos países componentes do BRICS. Santa Maria: Universidade Federal de Santa Maria, 2014. (Dissertação de mestrado). Disponível em: <http://cascavel.ufsm.br/tede// tde_arquivos/2/TDE-2015-09-24T095247Z6537/Publico/MENDES, CARLOS AUGUSTO NOGUEIRA.pdf> . Acesso em: 25 out. 2017.

Miketa, A. Analysis of energy intensity developments in manufacturing sectors in industrialized and developing countries. Energy Policy, v. 29, n. 10, p. 769-775, 2001. https://doi.org/10.1016/S0301-4215(01)00010-6

MMA - Ministério do Meio Ambiente. Entenda o acidente de Mariana e suas consequências para o meio ambiente. 2015. Disponível em: <http://www.brasil.gov.br/meio-ambiente/2015/ 12/entenda-o-acidente-de-mariana-e-suasconsequencias-para-o-meio-ambiente $>$. Acesso em: 05 fev. 2017.

MMA - Ministério do Meio Ambiente. Plano de ação para produção e consumo sustentáveis - PPCS. Brasília: MMA, 2014. (Relatório do primeiro ciclo de implementação). Disponível em: <http://www.mma.gov.br/ responsabilidade-socioambiental/producao-econsumo-sustentavel/plano-nacional>. Acesso em: 05 fev. 2017.
MME - Ministério de Minas e Energia. Consumo de energia elétrica no Brasil cai 0,9\% em 2016. Disponível em: $<$ http://www.epe.gov.br/sites-pt/publicacoesdados-abertos/publicacoes/Publicacoes Arquivos/publicacao-153/topico-155/Resenha Mensal do Mercado de Energia Elétrica - Junho 2016.pdf>. Acesso em: 01 out. 2017.

Morais, L. C. Estudo sobre o panorama da energia elétrica no Brasil e tendências futuras. Bauru: UNESP, 2015. (Dissertação de mestrado). Disponível em: $<$ https://alsafi.ead.unesp.br/bitstream/handle/11 449/132645/000852309.pdf $>$. Acesso em: 20 set. 2017.

OCDE - Organização para a Cooperação e Desenvolvimento Econômico. Avaliações de Desempenho Ambiental. 2015. Disponível em: $<$ https://www.oecd.org/ environment/countryreviews/EPR-Brasil-AR-Portugues.pdf $>$.

Acesso em: 23 out. 2017.

ONU - Organização das Nações Unidas. A cobertura florestal na China. 2016. Disponível em: <http://www.fao.org/brasil/pt/>. Acesso: 15 set. 2017.

Pastuco, J. A. M. Planejamento de longo prazo. Revista Economia e Energia, n. 35, 2002. Disponível em: <http://ecen.com/eee35/planejlog-praz.htm>. Acesso em: 26 mar. 2017.

Pegels, A. Renewable energy in South Africa: potentials, barriers and options for support. Energy Policy, v. 38, n. 9, p. 4945-4954, 2010. https://doi.org/10.1016/j.enpol.2010.03.077

Pelicioni, M. C. F. Educação ambiental, qualidade de vida e sustentabilidade. Saúde e Sociedade, v. 7, $\quad$ n. 2, p. 19-31, 1998. https://doi.org/10.1590/S010412901998000200003

Pereira, L. V.; Veloso, F.; Fan, Y.; Pan, Z. Infraestrutura: perspectivas do Brasil e da China. Rio de Janeiro: Elsevier, FGV, 2016.

Pereira, A. O. K.; Horn, L. F. R. Relações de consumo: meio ambiente. Caxias do Sul: EDUCS, 2009. Disponível em: $<$ https://fundacao.ucs.br/site/midia/arquivos/RC _MEIO_AMBIENTE_EBOOK.pdf $>$. Acesso em: 24 out. 2017.

Pinto Jr, H. Q.; Almeida, E. F.; Bomtempo, J. V. Economia da energia: fundamentos econômicos, evolução histórica e organização industrial. São Paulo: Campus, 2007.

Raj, P.; Saxena, A.; Gupta, S. Energy security na Indian perspective: the way forward. VIII Biennial International Conference and Exposition on Petroleum Geophysics, 2010. 
Disponível em: <https://www.spgindia.org/ 2010/137.pdf>. Acesso em: 23 out. 2017.

REN 21 - Renewable Energy Policy Network for the 21st Century. Renewables 2011 - Global Status Report. Disponível em: $<$ http://www.ren21.net/>. Acesso em: 23 out. 2017.

Ruddiman, W. F. The anthropogenic greenhouse era began thousands of years ago. Climate Change, v. 61, n. 3, p. 261-293, 2003. https://doi.org/10.1023/B:CLIM.0000004577.17 928.fa

Salazar, M. B. Demanda de energia na indústria brasileira: efeitos da eficiência energética. Piracicaba: Escola Superior de Agricultura Luiz de Queiroz, 2012. (Tese de doutorado).

Santos, L. B.. Papel do BRIC na economia mundial. Revista Mercator, v. 9, n. 19, p. 19-35, 2010. https://doi.org/10.4215/ RM2010.0919.0002

Say, J. B. Tratado de economia política. São Paulo: Nova Cultura, 1986.

Silva, A. M. D.; Herz, M. A Rússia e a estrutura institucional internacional para o desenvolvimento sustentável. Rio de Janeiro: Núcleo de Política Internacional e Agenda Multilateral, 2012. Disponível em: $<$ http://bricspolicycenter.org/homolog/uploads/t rabalhos/3994/doc/1046943232.pdf >. Acesso em: 20 out. 2017.

Tolmasquim, M. T; Guerreiro, A.; Gorini, R. Matriz energética brasileira: uma prospectiva. Novos Estudos CEBRAP, n. 79, n. 23, p. 47-69, 2007. https://doi.org/10.1590/S010133002007000300003
Tynkkynen, N.; Aalto, P. Environmental sustainability of Rusia's energy policy. In: Aalto, P. (Org.). Russia's energy policy: national, interregional and global levels. Cheltenham: Edward Elgar, 2012. p. 272-295.

Verissimo, A.; Nussbaum, R. Um resumo do status das florestas em países selecionados: nota técnica. Belém: Imazon, The Proforest Initiative, 2011. Disponível em: <http://www.lerf.eco.br/img/publicacoes/2011_ 09 Um Resumo do Status das Florestas em Paises Selecionados Nota Tecnica.pdf $>$. Acesso em: 21 out. 2017.

Zago, L. Discussões sobre a questão ambiental na China: impactos e perspectivas. 2014. Disponível em: <http://climacom.mudancas climaticas.net.br/?p=1828>. Acesso em: 23 out. 2017.

Informação da Licença: Este é um artigo Open Access distribuído sob os termos da Licença Creative Commons Attribution, que permite uso irrestrito, distribuição e reprodução em qualquer meio, desde que a obra original seja devidamente citada. 